\title{
Effectiveness of double tie-over dressing compared with bolster dressing
}

\author{
Seo Hyung Lee, Yu Jin Kim \\ Department of Plastic and Reconstructive Surgery, Gachon University Gil Medical Center, Incheon, Korea
}

Background Skin grafting is a commonly performed operation in plastic and reconstructive surgery. The tie-over dressing is an effective technique to secure the grafted skin by delivering persistent downward pressure. However, if an additional dressing is required due to incomplete graft healing, the process of re-implementing the tie-over dressing may be frustrating for both patients and surgeons. Therefore, we introduce the double tie-over dressing, which readily allows for an additional tie-over dressing after the first dressing, and we present a comparison of its effectiveness with that of the simpler bolster dressing.

Methods Of 128 patients with a skin defect, 69 received a double tie-over dressing and 59 patients received a simple bolster dressing. Using the independent t-test, the mean healing time, which was defined as the mean time it took for the wound to heal completely so that no additional dressing was required and it was washable with tap water, was compared between the 2 groups in both the head and neck region and in other areas.

Results The mean healing time for the head and neck region in the double tie-over dressing group was $9.19 \pm 1.78$ days, while it was $11.05 \pm 3.85$ days in the bolster dressing group. The comparison of the 2 groups by the independent t-test revealed a P-value of 0.003 for the mean healing time.

Conclusions In the head and neck area, the double tie-over dressing required less time to heal than the simple bolster dressing.

Keywords Bandages / Wounds and injuries / Skin transplantation / Occlusive dressings / Dermatologic surgical procedures

\author{
Correspondence: Yu Jin Kim \\ Department of Plastic and \\ Reconstructive Surgery, Gachon \\ University Gil Medical Center, \\ 21 Namdong-daero 774beon-gil, \\ Namdong-gu, Incheon 21565, Korea \\ Tel: +82-1577-2299 \\ Fax: +82-32-460-2398 \\ E-mail: pseugene@gilhospital.com
}

\section{INTRODUCTION}

Skin grafting is one of the most commonly performed techniques in the field of plastic and reconstructive surgery. Prior to grafting, matching the skin color and texture and minimizing donor site morbidity are important considerations; however, the primary requirement for successful grafting and graft survival is the application of even pressure throughout the bed by a carefully designed dressing [1]. The traditional methods of skin graft stabilization include the tie-over dressing, the bolster dressing, skin staples, sterilized rubber bands, negative-pressure dressings, and fibrin glues, but there is no consensus on the optimal method $[2,3]$.

The simple tie-over dressing is a well-known method, although many modifications of the classic technique have been described, such as a stapled tie-over stent, a transparent gas bag tie-over, a tie-over with a sports jacket clip, and a tie-over dressing with external wire-frame fixation and the tension suture 
technique [4-7]. The simple tie-over technique is widely used because of its simplicity. It is especially useful in the head and neck areas, where bony prominences create curvatures, thereby making it difficult to use external devices such as negative-pressure dressings or silicone tubing. However, when additional dressing is required due to incomplete graft healing, the process of re-implementing the traditional tie-over dressing may be frustrating for both patients and surgeons. It requires local anesthesia, and other compressive dressings may not guarantee sustained downward pressure to the same extent as the tie-over dressing. We thereby introduce the double tie-over dressing, which readily allows for an additional tie-over dressing after removal of the first dressing. We further present a comparison of the effectiveness of the double tie-over dressing with the simpler bolster dressing in terms of healing time.

\section{METHODS}

Between October 2013 and August 2016, skin defects from 128 patients were reconstructed with either a full-thickness skin graft (FTSG) or a split-thickness skin graft (STSG). This study was carried out in compliance with the Declaration of Helsinki, and written informed consent and permission were obtained prior to taking all photographs. After wound debridement, FTSGs were harvested from either the supraclavicular region or the groin, depending on the color and texture of the recipient site. STSGs were harvested from the lateral thigh in all cases. A total of 69 patients received the double tie-over dressing. The harvested skin was laid onto the defect and sutured with either 4-0 or 5-0 Mersilk (Ethicon Inc., Somerville, NJ, USA), depending on the location. While making the double tie-over, the first tie was made with long silk thread dangling on one end, and after finishing the knot, another silk thread with the same length was placed at the opposite end. These double tie-over threads were placed evenly, so that adequate pressure could be delivered to the grafted skin after completing the dressing. In cases requiring additional sutures to secure the graft, simple nylon or silk sutures were placed along the margin and center of the grafted skin, without leaving long threads dangling (Fig. 1A, B).

A non-adherent dressing was applied using Bactigras (Smith \& Nephew, London, UK) a paraffin tulle coated with chlorhexidine, and an antibiotic ointment was applied over it. Following this, cotton balls soaked in saline (for dressings in the head and neck area) or betadine were placed over it to create sufficient bulk for compression (Fig. 1C). Only one end of the silk threads was used for this first-time tie-over, and the leftover threads were intertwined with each other (Fig. 1D). On postoperative day 5 , the intertwined threads were uncoiled, and the tie-over dressing was removed to check for graft survival. If required, an additional tie-over dressing was made in exactly the same manner with the remaining silk threads and kept in place for 3-5 days, depending on the condition of the graft take.

\section{Fig. 1. A traumatic skin defect on the index finger}

(A) An image that was taken after debridement of the wound bed. (B) The double tieover dressing was made by creating a knot with 2 strands of long silk threads on each end. (C, D) A non-adherent dressing with betadine-soaked cotton balls was placed, and only 1 strand from each knot was tied over, leaving the other strand for an additional tie-over dressing if needed after removing the first dressing.
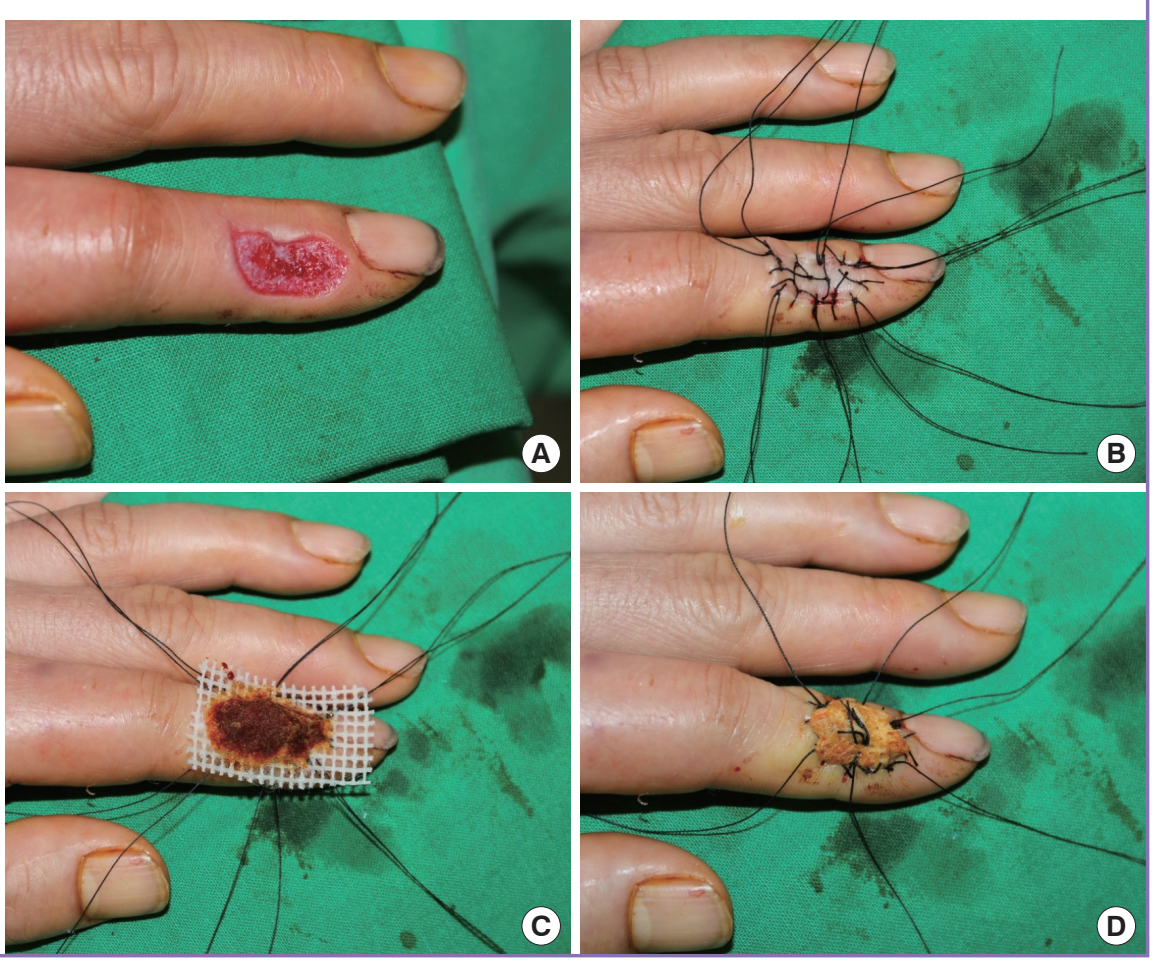
For the 59 patients who received a bolster dressing, the harvested skin was laid over the defect, and sutured with either 5-0 or 6-0 nylon (Ailee Co., Busan, Korea), depending on the location. In cases requiring additional sutures to secure the graft, simple nylon sutures were placed in the center of the grafted skin for fixation. The same non-adherent dressing was applied, and saline or betadine-soaked pieces of cotton balls were placed for compression. The molding was secured with simple taping.

Using the independent $\mathrm{t}$-test, we compared the mean healing time, which was defined as the mean time it took for the wound to heal completely, so that no additional dressing was required and it was washable with tap water, between the 2 groups. All statistical analyses were performed using $\mathrm{R}$ version 3.3.1 (The $\mathrm{R}$ Foundation for Statistical Computing, Vienna, Austria), and Pvalues of less than 0.05 were considered to indicate statistical significance.

\section{RESULTS}

Demographic information about the patients is presented in Table 1. Their overall mean age was 49.35 years (range, $7-90$ years). The etiologic conditions were skin malignancy $(n=39)$,

Table 1. Demographics of patients involved in the study

\begin{tabular}{|c|c|c|}
\hline & $\begin{array}{c}\text { Double tie-over } \\
\text { dressing }\end{array}$ & Bolster dressing \\
\hline No. of patients & 69 & 59 \\
\hline Sex (male:female) & $38: 31$ & $33: 26$ \\
\hline Age $(y r)^{a)}$ & $53.59 \pm 23.48$ & $44.39 \pm 17.50$ \\
\hline \multicolumn{3}{|l|}{ Location } \\
\hline Head and neck & 52 & 39 \\
\hline Others & 17 & 20 \\
\hline \multicolumn{3}{|l|}{ Indication ${ }^{\text {b) }}$} \\
\hline Malignancy & $29(25)$ & $10(8)$ \\
\hline Trauma & $23(20)$ & $20(13)$ \\
\hline Burn & $9(1)$ & $24(15)$ \\
\hline Scar-related & $5(3)$ & $5(3)$ \\
\hline Nevus & $3(3)$ & 0 \\
\hline \multicolumn{3}{|l|}{ Graft type } \\
\hline STSG & $45(31)$ & $40(30)$ \\
\hline FTSG & $24(21)$ & $19(9)$ \\
\hline \multicolumn{3}{|l|}{ Graft size $\left(\mathrm{cm}^{2}\right)^{\text {a) }}$} \\
\hline Head and neck area & $7.36 \pm 6.16$ & $9.21 \pm 11.84$ \\
\hline Other areas & $13.59 \pm 20.35$ & $12.98 \pm 14.97$ \\
\hline \multicolumn{3}{|l|}{ Healing time (day)a) } \\
\hline Head and neck area & $9.19 \pm 1.78$ & $11.05 \pm 3.85$ \\
\hline Other areas & $10.53 \pm 3.10$ & $11.30 \pm 3.31$ \\
\hline \multicolumn{3}{|l|}{ Complications } \\
\hline Hematoma & 4 & 5 \\
\hline Seroma & 0 & 1 \\
\hline \multicolumn{3}{|c|}{ 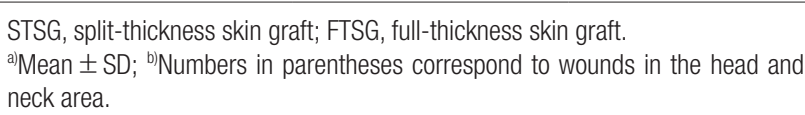 } \\
\hline
\end{tabular}

trauma ( $n=43)$, burn $(n=33)$, scar-related issues $(n=10)$, and nevus $(\mathrm{n}=3)$. Of the 128 patients, 85 underwent STSG, and 43 underwent FTSG. The most frequent defect sites were in the head and neck region $(\mathrm{n}=91)$.

In the double tie-over dressing group, the mean age was 53.59 years (range, 7-90 years); the mean healing time was $9.19 \pm 1.78$ days for wounds in the head and neck region, and 10.53 \pm 3.10 days for wounds in other areas. In the bolster dressing group, the mean age was 44.39 years (range, $10-78$ years). The mean healing time was $11.05 \pm 3.85$ days for wounds in the head and neck region, and $11.30 \pm 3.31$ days for wounds in other areas.

The independent $t$-test revealed a statistically significant difference in the mean healing time between the 2 dressing groups for wounds in the head and neck region $(P=0.003)$, whereas no statistically significant difference in the mean healing time was found for wounds in other areas $(\mathrm{P}=0.473)$. Furthermore, no statistical significance was observed in graft size in either the head and neck region or other areas $(\mathrm{P}=0.335$ and $\mathrm{P}=0.918$, respectively).

Four cases of hematoma were seen in the double tie-over dressing group, and five cases of hematoma and one case of seroma were noted in the bolster dressing group. Concerns regarding adequate pressure delivery were resolved, since all grafted skin took completely, without additional surgery. All the wounds that experienced a complication healed with a prolonged dressing period. Some patients were concerned with the elevated suture margins immediately after the dressing was removed, but all such cases resolved within the 6-month followup period. Fig. 2 presents the status of FTSG take in a patient after basal cell carcinoma removal on the cheek. Although elevated suture margin and focal pigmentation persisted a month after excision (Fig. 2E), these problems resolved within 6 months, when outstanding skin color match and texture were observed (Fig. 2F).

\section{DISCUSSION}

The tie-over suture is one of the most common methods of generating pressure on a dressing in order to splint a graft to its bed, and this requires the placement of interrupted silk sutures around the circumference of the graft [8]. In our technique, 2 silk threads were placed, allowing for an additional tie-over dressing. The traditional tie-over suture and its modifications lack this opportunity for a second chance, making the application of even pressure to the graft impractical when graft stabilization is inadequate after removal of the first dressing.

We compared the effectiveness of this double tie-over dressing with the bolster dressing in the head and neck region and other 


\section{Fig. 2. A basal cell carcinoma on the cheek}

$(A, B)$ The basal cell carcinoma was located on the right cheek just below the temple. We designated a safety margin of $3 \mathrm{~mm}$. (C) The defect margin was proven to be cancer-free by frozen biopsy. (D) A full-thickness skin graft was performed with a double tie-over dressing. (E) A month after the operation, focal skin pigmentation with elevated margin of the graft was observed, but (F) all issues had satisfactorily resolved by 6 months.
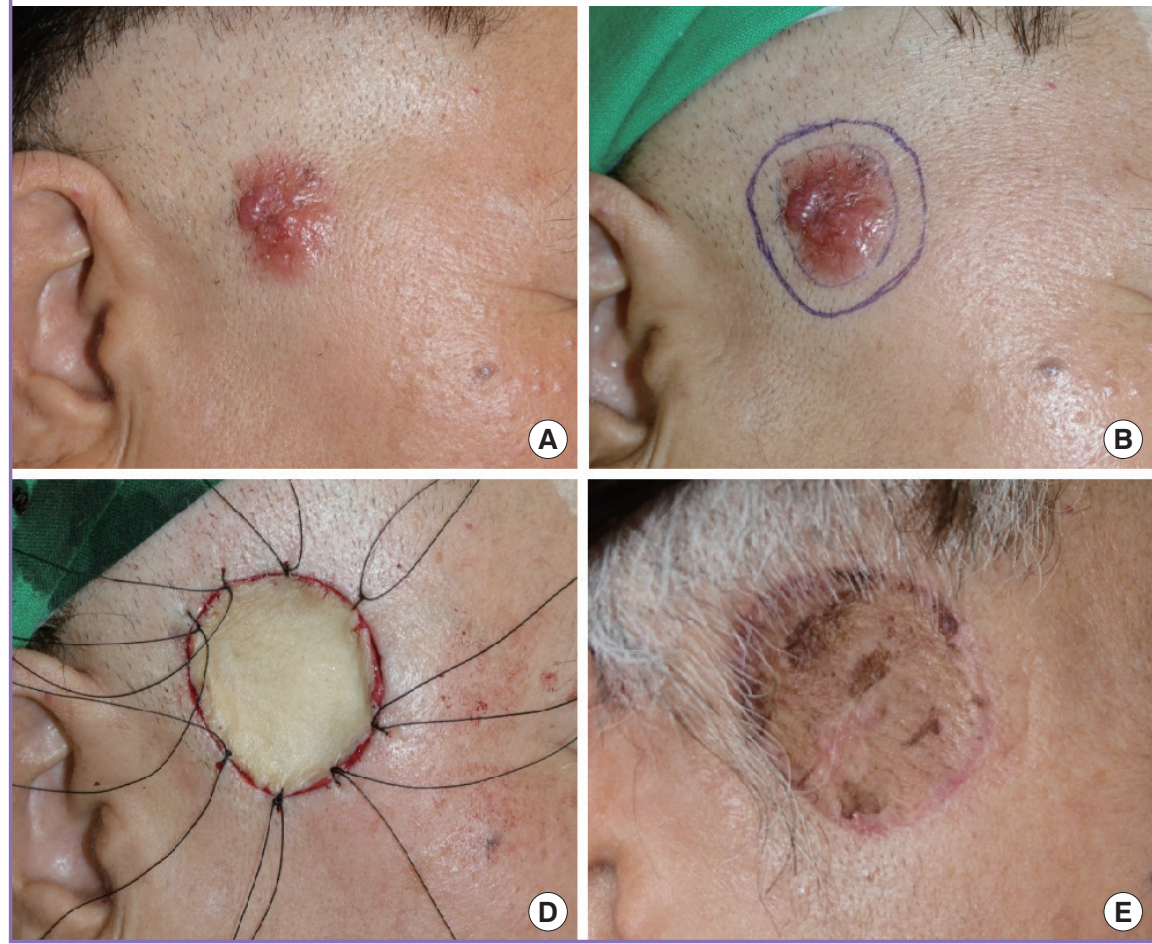
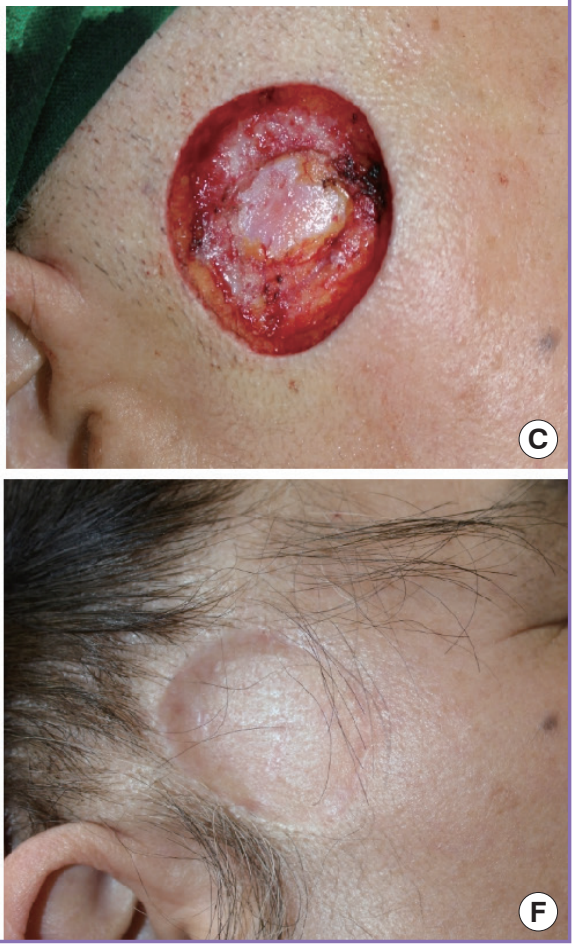

areas. In terms of the mean healing time, the P-value of 0.003 demonstrates that the double tie-over dressing required less time to heal when applied to wounds in the head and neck region. However, no statistical significance in the mean healing time was observed for wounds in other areas $(P=0.473)$. Since wound size is one of the most important factors that can influence time to heal, graft size was also compared between the 2 groups. The graft size in both the head and neck region and other areas did not significantly differ between the double tie-over dressing group and the bolster dressing group, with P-values of 0.335 and 0.918 , respectively.

The most common cause of skin graft failure is the collection of blood or serous fluid beneath the graft, and therefore, immobilization and close contact of the graft with the bed is an important factor for increasing the success of the skin graft [9]. We encountered nine cases of hematoma and one case of seroma, all of which resolved completely without any secondary intervention. All cases of hematoma were on the scalp, which has a rich vascular supply.

In order to prevent hematoma or seroma formation, it has been proposed that a minimum of $25 \mathrm{~mm} \mathrm{Hg}$ above the capillary pressure is required, but excess pressure may result in tissue necrosis [10-12]. We believe that the double tie-over dressing sustained a balanced pressure, so that serious hematoma or seroma leading to graft loss or tissue necrosis from compromised blood flow was not encountered in our study. Based on our findings, patients in whom the double tie-over dressing is used for a wound in the head and neck region can expect earlier recovery or discharge than if a simple bolster dressing were to be used, without an elevated risk of developing serious complications.

Our findings have the potential limitation that our sample size of wounds in other regions than the head and neck region was small, and the term "other region" is in fact an oversimplification for comparing the effectiveness of dressing techniques. A larger sample size and specific body regions should be analyzed in further studies to determine whether this double tie-over dressing technique is suitable. In addition, measuring the downward pressure exerted on the grafted skin in the double tie-over dressing would have provided clearer insights regarding whether this method generated enough force to prevent hematoma or seroma formation.

When the tie-over dressing is removed to check for graft survival and incomplete graft healing is encountered, re-implementing the tie-over dressing requires local anesthesia and is time-consuming. Based on the results of our study, we recommend applying the double tie-over dressing technique, which 
readily allows for an additional tie-over dressing after removal of the first dressing, to wounds in the head and neck region in order to maintain a persistent downward pressure, reducing the healing time.

\section{NOTES}

\section{Conflict of interest}

No potential conflict of interest relevant to this article was reported.

\section{Patient consent}

The patients provided written informed consent for the publication and the use of their images.

\section{REFERENCES}

1. Blair VP, Brown JB. The use and uses of large split skin grafts of intermediate thickness. Plast Reconst Surg 1968;42:6575.

2. Joyce KM, Joyce CW, Mahon N, et al. Use of a barbed suture tie-over technique for skin graft dressings: a case series. Arch Plast Surg 2015;42:341-5.

3. Ogawa R, Hyakusoku H, Ono S. Useful tips for successful skin grafting. J Nippon Med Sch 2007;74:386-92.
4. Niranjan NS. A modified tie-over dressing for skin grafts. $\mathrm{Br}$ J Plast Surg 1985;38:415-8.

5. Jo HJ, Kim JS, Kim NG, et al. Redoable tie-over dressing using multiple loop silk threads. Arch Plast Surg 2013;40:25962.

6. Ergen D, Tan O, Bayindir O. Tension suture technique for skin graft fixation: a novel alternative to tie-over dressing. Burns 2006;32:778-9.

7. Budi S, Rados J, Stanec Z. A sports jacket clip: a simple method of securing tie-over dressings. J Plast Reconstr Aesthet Surg 2009;62:e495-6.

8. Misra A, Belcher HJ. A new loop suture tie-over technique for skin graft dressings. J Hand Surg Br 2002;27:129-33.

9. Bektas CI, Kankaya Y, Ozer K, et al. A tie-over dressing using a silicone tube to graft deep wounds. Arch Plast Surg 2013;40:711-4.

10. Seymour FK, Giele HP. Tie-overs under pressure. Br J Plast Surg 2003;56:494-7.

11. Joyce CW, Joyce KM, Mahon N, et al. A novel barbed suture tie-over dressing for skin grafts: a comparison with traditional techniques. J Plast Reconstr Aesthet Surg 2014;67: 1237-41.

12. Joyce CW, Joyce KM, Kennedy AM, et al. The running barbed tie-over dressing. Plast Reconstr Surg Glob Open 2014;2:e137. 